\title{
Implementation of a Telechemotherapy Module in the Peruvian Jungle with Adequate Quality of Life: Breaking the Access Gaps to Health with Teleoncology
}

\author{
Tatiana Vidaurre ${ }^{1}$, Jule Vásquez ${ }^{1}$, Fernando Valencia ${ }^{1}$, Cindy Alcarraz ${ }^{1}$, Luis Más ${ }^{1}$, \\ Nataly Poma1, Litol Becerra², Gino Rodriguez², Socorro Saldaña², Pepe Diaz ${ }^{3}$, Silvia Neciosup ${ }^{1}$, \\ Karina Aliaga1, Roxana Regalado3, Miriam Salazar3, Kavita Sarwal', Simon Sutcliffe4, \\ Julio Abugattas³ , Carlos Castañeda1, Mónica Calderón1, Hugo Fuentes¹, Henry Gómez ${ }^{1}$ \\ ${ }^{1}$ Medical Oncologist, Instituto Nacional de Enfermedades Neoplasicas (INEN), Lima, Peru \\ ${ }^{2}$ Hospital II-E Lamas, San Martin, Peru \\ ${ }^{3}$ Instituto Nacional de Enfermedades Neoplasicas (INEN), Lima, Peru \\ ${ }^{4}$ International Cancer Control Congress Association (ICCCA), Vancouver, Canada \\ Email: *vidaurret@gmail.com
}

How to cite this paper: Vidaurre, T., Vásquez, J., Valencia, F., Alcarraz, C., Más, L., Poma, N., Becerra, L., Rodriguez, G., Saldaña, S., Diaz, P., Neciosup, S., Aliaga, K., Regalado, R., Salazar, M., Sarwal, K., Sutcliffe, S., Abugattas, J., Castañeda, C., Calderón, M., Fuentes, H. and Gómez, H. (2019) Implementation of a Telechemotherapy Module in the Peruvian Jungle with Adequate Quality of Life: Breaking the Access Gaps to Health with Teleoncology. Journal of Cancer Therapy, 10, 677-691. https://doi.org/10.4236/jct.2019.108056

Received: June 26, 2019

Accepted: August 18, 2019

Published: August 21, 2019

Copyright $\odot 2019$ by author(s) and Scientific Research Publishing Inc. This work is licensed under the Creative Commons Attribution International License (CC BY 4.0).

http://creativecommons.org/licenses/by/4.0/

\begin{abstract}
Background: Cancer is a leading cause of death worldwide as well as in Peru. The national cancer plan includes decentralization, but one of the greatest barriers is our complicated geography. San Martin is a department located in the Peruvian jungle where there are no public services for cancer care. Our aim was to implement a "distance telemedicine-enabled" outpatient chemotherapy module, monitored by oncologists. Methods: The implementation was conducted in 3 stages: 1) Planning and Organization: working teams were formed, a chemotherapy room was developed and people were trained. 2) Execution: patients from San Martín region, aged $>18$ years with pathological confirmation of cancer, requiring systemic chemotherapy, ECOG $<3$, and first course of chemotherapy received at INEN without adverse reaction were selected. 3) Evaluation: adverse events, cost-user evaluation and quality of life (QoL) were assessed. Results: By November 2015, a module with a chemotherapy room with 18 chairs, a pharmacy, a hospitalization room, 1 medical office, a training room, a nutrition area, and a nursing station was implemented. 3 physicians, 3 nurses and 1 pharmacist were trained. Through March 2018, 501 sessions of teleoncology were completed to deliver 232 cycles of chemotherapy for 56 patients aged $19-78$ years with different solid tumors, with no serious adverse event, without negatively affecting their QoL,
\end{abstract}


and with an average out-of-pocket expense saving of 500 PEN. Conclusions: Using information and communication technology, a telechemotherapy module was successfully implemented in the Peruvian jungle, without adversely affecting the QoL of patients. Neither patients nor family members needed to travel to Lima to receive chemotherapy. This first program can be replicated in other rural and remote regions through non-specialized personnel and facilities, providing chemotherapy services equivalent to a tertiary center through trained health care professionals, supported through telemedicine.

\section{Keywords}

Telechemotherapy Module, Cancer Treatment, Urban Tertiary Center, Teleoncology

\section{Introduction}

Cancer is the second leading cause of death worldwide and was responsible for 8.8 million deaths in 2015. Approximately $70 \%$ of deaths occur in low and middle-income countries [1]. More than $90 \%$ of high-income countries report having comparable treatment services available to less than $30 \%$ of low-income countries [1]. According to Globocan 2012, in Peru, the most prevalent cancers are cervical, gastric, breast, prostate and colorectal cancer [2].

Telemedicine applied to teleoncology began with the use of videoconferencing in the evaluation of the care of cancer patients and goes back to 1990 [3]. Subsequently, cancer patient's satisfaction regarding teleoncology has been evaluated in a rural area [4], for medical evaluation and tumor clinical-pathology consultation [5] [6] [7], and to prospectively evaluate the feasibility of administering chemotherapy in rural and remote areas [8] [9] [10].

INEN (The Instituto Nacional de Enfermedades Neoplásicas) launched "Plan Esperanza" in 2012 to improve population-based cancer control outcomes through decentralization of oncological services, along with strategies that bring quality services closer to the patients' home and community [11]. 75\% of the cases referred to (INEN) are in advanced stages [12] and require systemic treatment (chemotherapy). In the Department of San Martín in the Peruvian jungle, cancer care is not provided in public health centers. Accordingly, an initiative to provide chemotherapy through a satellite module (telechemotherapy) was undertaken in the remote region of Lamas in the Peruvian Amazon.

Geographic barriers to access to oncological services and more specifically to administration of chemotherapy exist. This report addresses the implementation of a "distance telemedicine-enabled" outpatient chemotherapy module, monitored by INEN oncologists, in a non-specialized hospital in the Peruvian jungle, to determine whether the quality of life and costs of care were impacted by delivering care "closer to home". 


\section{Materials and Methods}

\subsection{Study Setting}

INEN receives referrals patients from across Peru. Around 300 annual new cases originate in San Martin, where Lamas Hospital is located (1100 Km from Lima). Approximately 80 patients from San Martin start chemotherapy each year at INEN.

The implementation of the National Cancer Plan for Peru (Plan Esperanza), has been essential to bring cancer care to rural and remote communities. With the implementation of the telechemotherapy module (TELECHEMO) and the administration of systemic chemotherapy, the quality of life, social and economic implications of delivering care closer to home were investigated.

\section{Implementation of the telechemoterapy module}

The Lamas Hospital, category II-E (second level of care), located in the Peruvian jungle, was selected for the implementation of TELECHEMO. The hospital has two pathologists, and no medical or radiation oncologists. The development process included 3 stages: 1) planning and organization, 2) execution or implementation and 3) monitoring and evaluation, each requiring several phases (Figure 1).

\subsection{Planning and Organization}

Four phases were addressed from December 2014 to November 2015.

Phase 1: Organization of the management team at INEN and the Health Establishment headquarters of the module, involving the appointment of the management team to oversee the signing of inter-institutional agreements, and the planning and appointment of technical, administrative and technological personnel for the creation of the TELECHEMO Module.

Phase 2: Site development/adaptation/improvement. Site development to cancer care and teleoncology activities were undertaken at Hospital II-E Lamas and at INEN. The areas necessary for development included chemotherapy preparation and biological safety, patient care, teleconferencing and administration. The Information and Communications Technology (ICT) team of INEN adapted to the technology available in the San Martín region by connecting to the Lamas hospital through videoconferencing sessions using Zoom or Webex platforms. These platforms require internet service with a minimum connection of $512 \mathrm{kbps}$ guaranteed at 50\%,1 Mbps optimal connection with 1:1 overbooking. The minimum computer equipment requirements for communication via video conferencing were Cisco video conferencing equipment model MX-300, high-resolution camera for INEN, webcam for Lamas Hospital, microphone speaker, laptop/PC i3, projector (for group presentations) or LCD 50. No equipment or technological barriers were identified in the connection of Lamas Hospital and INEN.

Phase 3: Organization of personnel. Lamas Hospital health personnel were designated according to their skill set to work in the TELECHEMO Module, 


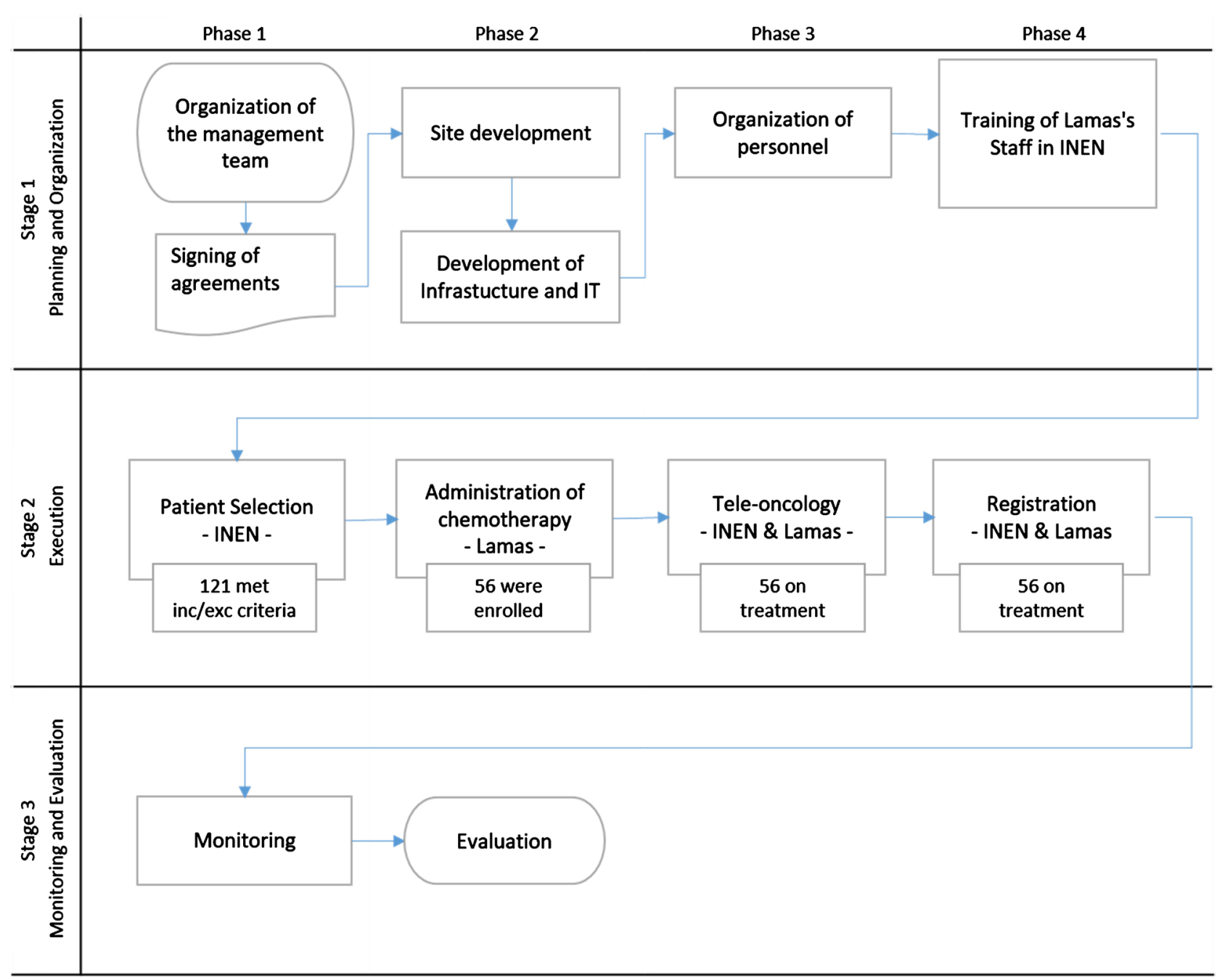

Figure 1. The study design comprising 3 phases: planning and organization, execution, and monitoring and evaluation.

thereby avoiding the hiring of new personnel. The TELECHEMO Module had one module coordinator, two general practitioners, one pharmacist, one nurse, one nursing technician and one computer technical support person.

Phase 4: Training of staff. All TELECHEMO Module health personnel received face-to-face training at INEN, customized to the specific needs of each role, prior to starting satellite chemotherapy module services.

The physicians received training in basic principles of cancer, chemotherapy, management of side effects, and prevention, diagnosis and treatment of the main types of cancer that are handled in the TELECHEMO modules (breast, ovary, lung, cervix and gastric). The nurses and the pharmacist received training according to their professional standards and practices.

\subsection{Execution}

Phase 1: Patient selection. Patient selection was carried out exclusively at INEN according to the following:

Inclusion criteria: 
- Patients aged 18 years and over, of any gender;

- Diagnosis of malignancy with pathological confirmation, requiring systemic chemotherapy;

- Residence in the area of the TELECHEMO module (San Martín region);

- Signed informed consent to undergo chemotherapy;

- Insured by the comprehensive health insurance of Peru (SIS);

- Karnofsky performance score of $\geq 60$ or of ECOG $<3$;

- Life expectancy of $\geq 4$ months, normal bone marrow, kidney and liver function, and the first course of chemotherapy received at INEN without adverse reaction.

Exclusion Criteria:

- Uncontrolled co-morbid disease; contraindication to the administration of cytotoxic chemotherapy; pregnant;

- Participation in an ongoing INEN clinical trial.

Phase 2: Administration of chemotherapy. Chemotherapy was administered according to INEN policies and procedures regarding preparation, administration and safety.

Phase 3: Teleoncology. General meetings of the Program Coordinator, medical oncologists, nurses and pharmacists of INEN and the Lamas TELECHEMO Module work team were held once-weekly, and included discussion of new cases and/or therapy, work plans, medication and/or other technical issues.

Phase 4: Registration. Any interaction with the patient or discussion of information related to patient management e.g. clinical evaluations, application of chemotherapy, was recorded in the patient's medical record at Lamas Hospital and at INEN.

\subsection{Monitoring and Evaluation}

Phase 1: Monitoring. INEN assistance and technical teams (Departments of Medicine and Cancer Control) provided continuous monitoring and support for TELECHEMO.

Phase 2: Evaluation. Three program indicators were assessed: the proportion of patients living in the Lamas area assigned to the TELECHEMO module; the proportion of TELECHEMO module areas operating efficiently; and the proportion of patients in the INEN area of influence receiving the chemotherapy treatment in the TELECHEMO Module.

\section{Patients, Chemotherapy and Type of Cancer}

A descriptive analysis of enrolled patients, participating health personnel, oncological diagnoses, types of chemotherapy and/or hormone therapy, number of chemotherapy courses, number of chemotherapy sessions, description of early and late complications related to chemotherapy, adherence to treatment (percentage of the number of courses received from the number of courses prescribed in case of chemotherapy and continuity of hormone therapy for the in- 
dicated time) was recorded. The results are presented with a patient follow-up of 24 months from initiation of telechemotherapy.

Adverse events were graded according to the Common Terminology Criteria for Adverse Events version 4 (CTCAE V.4) [13].

\section{Cost-User Evaluation}

For the cost-user evaluation, a survey to assess the time it took patients on average to travel from their home to the chemotherapy room while in Lima or Lamas was taken. Additionally, a cost survey captured the experiences, food, lodging, transportation from home to the hospital in both Lima (INEN) and the Lamas Hospital.

\section{Assessment of Quality of Life}

A pilot study evaluating the quality of life of patients admitted from November to December 2015 was conducted using a questionnaire (EORTC QLQ-C30 v.3 of the European Organization for Research and Treatment of Cancer) was applied at the beginning of treatment (baseline) and at first and third month of treatment.

The questionnaire is validated in Spanish [14] [15] and evaluates the perception of global health, the different spheres of functional status, and the intensity of symptoms related to the disease, each scored individually with four to seven possible answers, each worth 1, 2, 3, 4, 5, 6 or 7 points. Questions are grouped according to the parameter they evaluate (e.g. social function) and their individual scores totaled using formulae to obtain a value from 0 to 100 for all parameters. Higher global scores $(>60)$ for functional attributes represent a lesser alteration of functional status and, by implication, a more satisfactory quality of life. However, high scores in the symptomatic scales represent relevant and significant symptomatology and a worse functional level.

\section{Ethical considerations}

The project was approved by the Ethics Committee of INEN. All patients entering the program signed informed consent.

\section{Results}

\subsection{Implementation Indicators}

\section{Infrastructure}

The module consists of a chemotherapy area with 18 chairs, a pharmacy area including drug preparation and handling, a hospitalization room, 1 office, a training room, a nutrition area, a nursing station and a waiting room.

\section{Training for health personnel}

During the implementation process, health professionals were trained for three months: two Lamas Hospital II general practitioners were trained in the evaluation of cancer patients in outpatient, in inpatient, emergency and ambulatory chemotherapy room practice. Three nurses were trained in verification, 
administration and monitoring of chemotherapy, and in palliative care for terminally ill patients. One pharmacist was trained in the preparation, dispensing and distribution of chemotherapy.

\subsection{Process Indicators}

The number of patients admitted to the TELECHEMO module, the number of chemotherapy cycles, the number of sessions for administration of chemotherapy, and complications secondary to treatment were recorded.

\section{Patients admitted to the TELECHEMO module}

From November 2015 to March 2018, 121 patients met the inclusion and exclusion criteria and 56 patients $(46.3 \%)$ were enrolled in the program. The clinical-pathological characteristics of the 56 patients are shown in Table 1 . The median age was 56 years, most were women, predominantly with advanced stages of disease. Chemotherapy was initiated at INEN and continued within the local social and family environment without alteration, according to the standards of administration of ambulatory chemotherapy at INEN i.e. supply of medicines, preparation of medicines in laminar flow hood by pharmacists with training in chemotherapy preparation, administration of chemotherapy and medical monitoring by trained nurses.

Table 1. Demographic characteristics for 56 subjects receiving treatment through distance telechemotherapy at Lamas Hospital.

\begin{tabular}{|c|c|c|}
\hline & $\mathrm{n}=56$ & $\%$ \\
\hline \multicolumn{3}{|l|}{ Age } \\
\hline Mean & 56 & \\
\hline Range & $19-78$ & \\
\hline \multicolumn{3}{|l|}{ Sex } \\
\hline Female & 41 & 73.2 \\
\hline Male & 15 & 26.8 \\
\hline \multicolumn{3}{|l|}{ Type of Diagnosis } \\
\hline Breast Cancer & 17 & 32.1 \\
\hline Cervical Cancer & 10 & 18.9 \\
\hline Gastric Cancer & 9 & 17.0 \\
\hline Ovarian Cancer & 5 & 9.4 \\
\hline Colon/Rectal Cancer & 4 & 7.5 \\
\hline Central Nervous System Cancer & 3 & 5.7 \\
\hline Hepatocellular Carcinoma & 3 & 5.7 \\
\hline Lung Cancer & 2 & 3.8 \\
\hline Other & 3 & 5.7 \\
\hline \multicolumn{3}{|l|}{ Clinical Stage } \\
\hline Metastatic & 41 & 73.2 \\
\hline Non-Metastatic & 15 & 26.8 \\
\hline
\end{tabular}




\section{Chemotherapy cycles administered}

232 cycles of chemotherapy were administered to 56 patients (Table 2). The procedures were supervised by medical oncologists from INEN.

501 sessions were required for the completion of 232 cycles of chemotherapy, some requiring more than one session per cycle.

\section{Side effects related to chemotherapy}

The first 19 patients were evaluated as a pilot to assess acute treatment complications and safety. No severe adverse events were reported.

- Early complications:

Despite being a complex treatment, no acute complications, including infusion reactions, were documented during chemotherapy application.

- Late complications:

Two $(10.5 \%)$ patients had grade 1 neuropathy secondary to treatment with taxanes, 3 (15.7\%) patients had grade 2 neutropenia and one (5.2\%) had grade 4 neutropenia (afebrile), one patient (5.2\%) presented with grade 1 anemia and one patient (5.2\%) grade 4 thrombocytopenia, manifesting with ecchymosis and resolving with adequate and timely support.

\section{Medical evaluation of enrolled patients (Teleconsultation)}

The medical teams at Lamas hospital and INEN held medical evaluation meetings before each cycle of chemotherapy $(n=232)$, and 215 medical consultations

Table 2. Chemotherapy regimens delivered per protocol through distance telechemotherapy at Lamas Hospital.

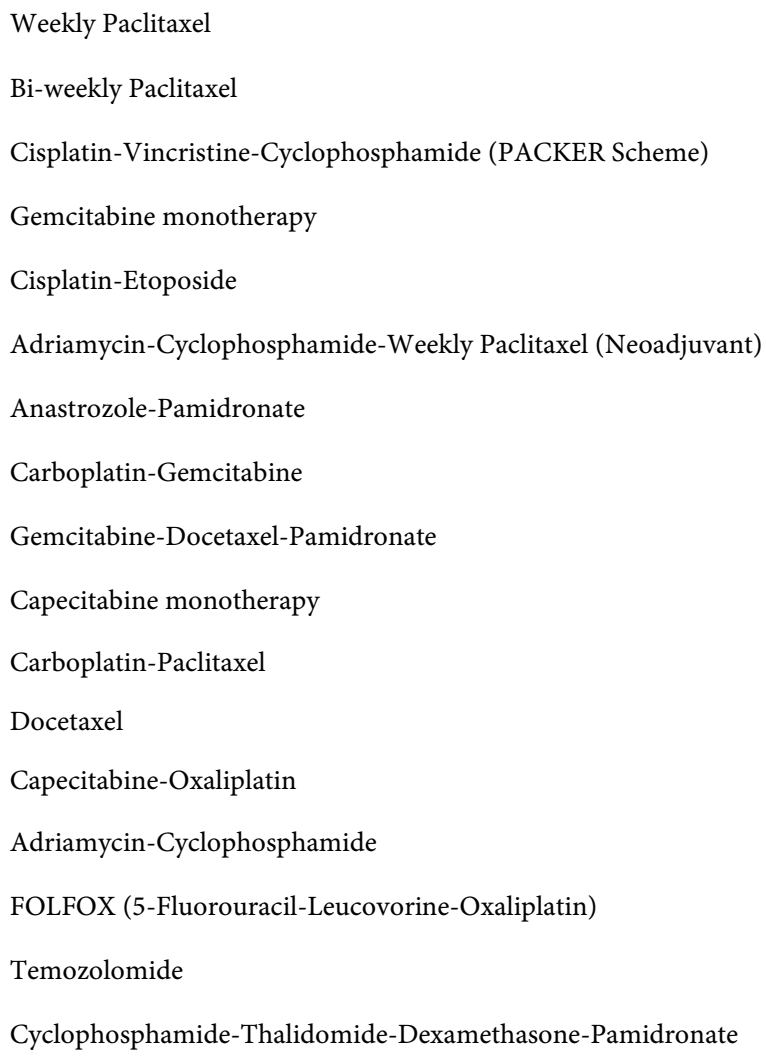


by teleconference. This included interviewing, monitoring, application of treatment and clinical case discussion. Meetings were held once a month to discuss cases and scheduling treatment at Lamas Hospital. The process can be viewed through the following link https://youtu.be/a30MAY3t0Co.

\section{Adherence to treatment}

Complete adherence to treatment was achieved, i.e. a zero drop-out rate. The quality of care was evaluated through monitoring and auditing.

\subsection{Cost/User Indicators}

\section{Transfer time}

Patients residing in the San Martin region have 2 transport options to travel to Lima, the first overland by interprovincial bus with a route between $1100-1400$ $\mathrm{km}$ in $22-25$ hours respectively, and a return journey consuming between 48 and 54 hours.

The second is by a 1.25 -hour flight of approximately $615 \mathrm{~km}$, but being significantly more expensive. In Lima, the median time for patients to move from the place where they stayed (family's home or hotel rooms, hostels) to the chemotherapy room was around 6.5 hours (range: $2.5-12$ hours); in the city of Lamas the median time was 2.5 hours (range: 1.0 - 5 hours) i.e. a saving of almost 4 hours for patients on the day of their treatment.

\section{Indirect costs for comprehensive oncological care (Table 3)}

A survey of indirect costs related to the entire care process was conducted.

Indirect costs usually assumed by the patient and his/her family considered were food, lodging, transportation from home to hospital, and transportation from San Martin region to Lima. Receiving treatment in Lima incurs an average expenditure of USD 159 (PEN 539), compared with USD 10 (PEN 34) for those receiving treatment at Lamas Hospital, with the average cost savings in basic family food of an average of USD 150 (PEN 502). All patients had full free access and coverage for their treatment (by SIS under the Plan Esperanza program).

Table 3. Out-of-pocket expenses incurred per person for each cycle of chemotherapy according to administration of chemotherapy in Lima or by remote telechemotherapy at Lamas Hospital.

\begin{tabular}{ccccc}
\hline & \multicolumn{2}{c}{ INEN } & \multicolumn{2}{c}{ LAMAS } \\
\cline { 2 - 5 } & Mean & Range & Mean & Range \\
\hline Food Costs & 25.45 & $(10-40)$ & 10.31 & $(0-30)$ \\
Lodging Costs & 2.73 & $(0-25)$ & 2.69 & $(0-35)$ \\
Local Transportation (Home to Hospital) & 21.73 & $(0-60)$ & 20.92 & $(4-60)$ \\
Inter-Provincial Transportation & 489.17 & $(120-800)$ & - & - \\
(San Martin - Lima - San Martin) & & & 33.92 & \\
Total & 539.08 & & 10.31 & \\
Total in USD & 163.85 & & & \\
\hline
\end{tabular}

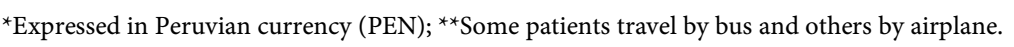




\subsection{Quality Indicator}

Quality of life (QoL) (Figures 2-4)

Results of a pilot study of QoL on patients enrolled in the first two months are shown in Figure 2 to Figure 4. Improvement in perceived global health status/ quality of life (Figure 2), and improvement in the different spheres of functional performance, particularly social and emotional well-being (Figure 3) were noted. Symptoms tended to decrease with time, consistent with improved control of disease with chemotherapy, with patients reporting a marked decrease in perceived economic difficulties over the 3-month treatment period (Figure 4).

\section{Global health status / QoL}

100.00

Global health status

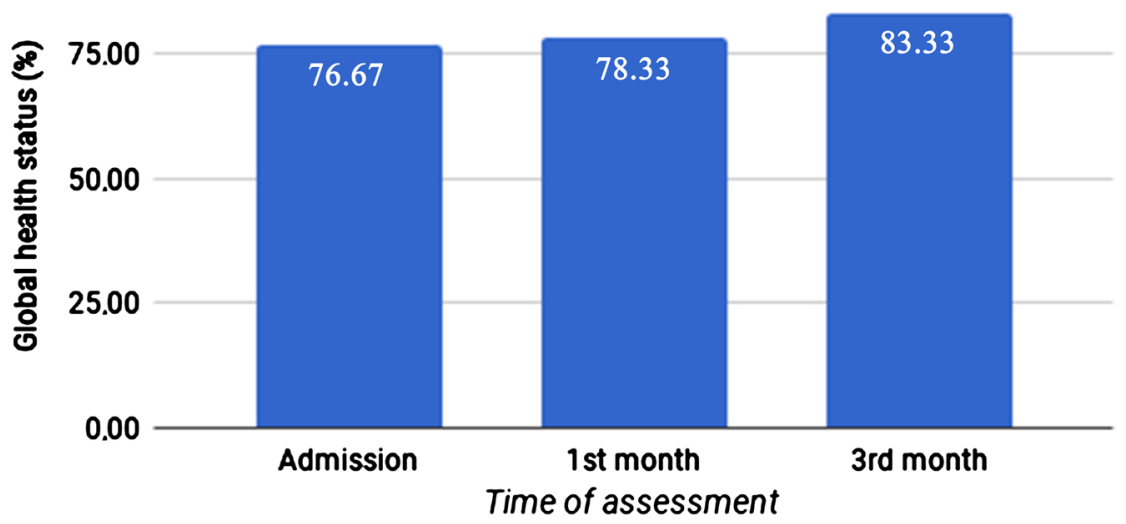

Figure 2. Global health status/quality of life assessed at baseline, 1st and 3rd month post initiation of therapy.

\section{Functional scales / QoL}

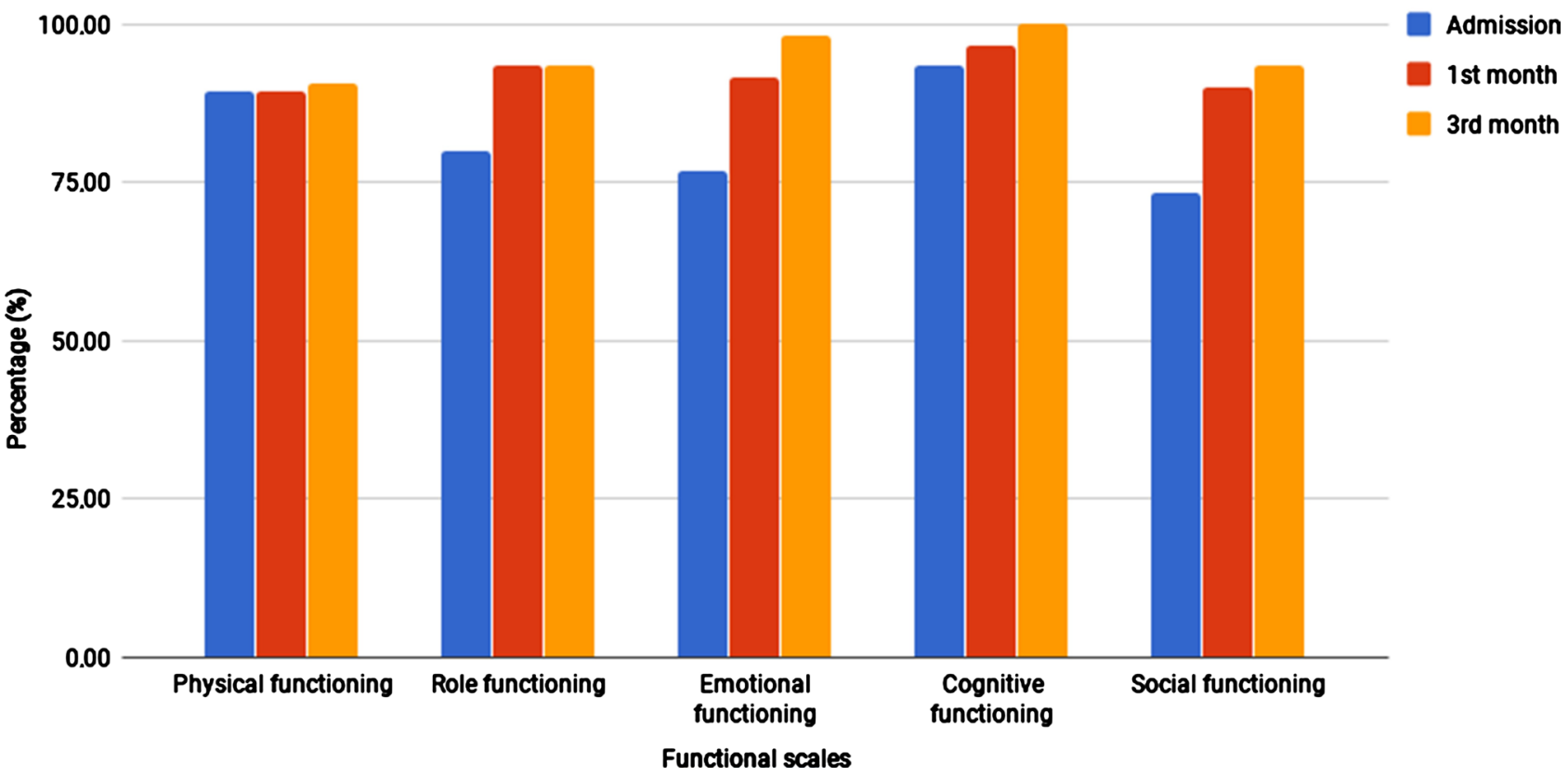

Figure 3. Functional scales/quality of life assessed at baseline, 1st and 3rd month post initiation of therapy. 


\section{Symptom scales / QoL}

40.00

Admission

1 st month

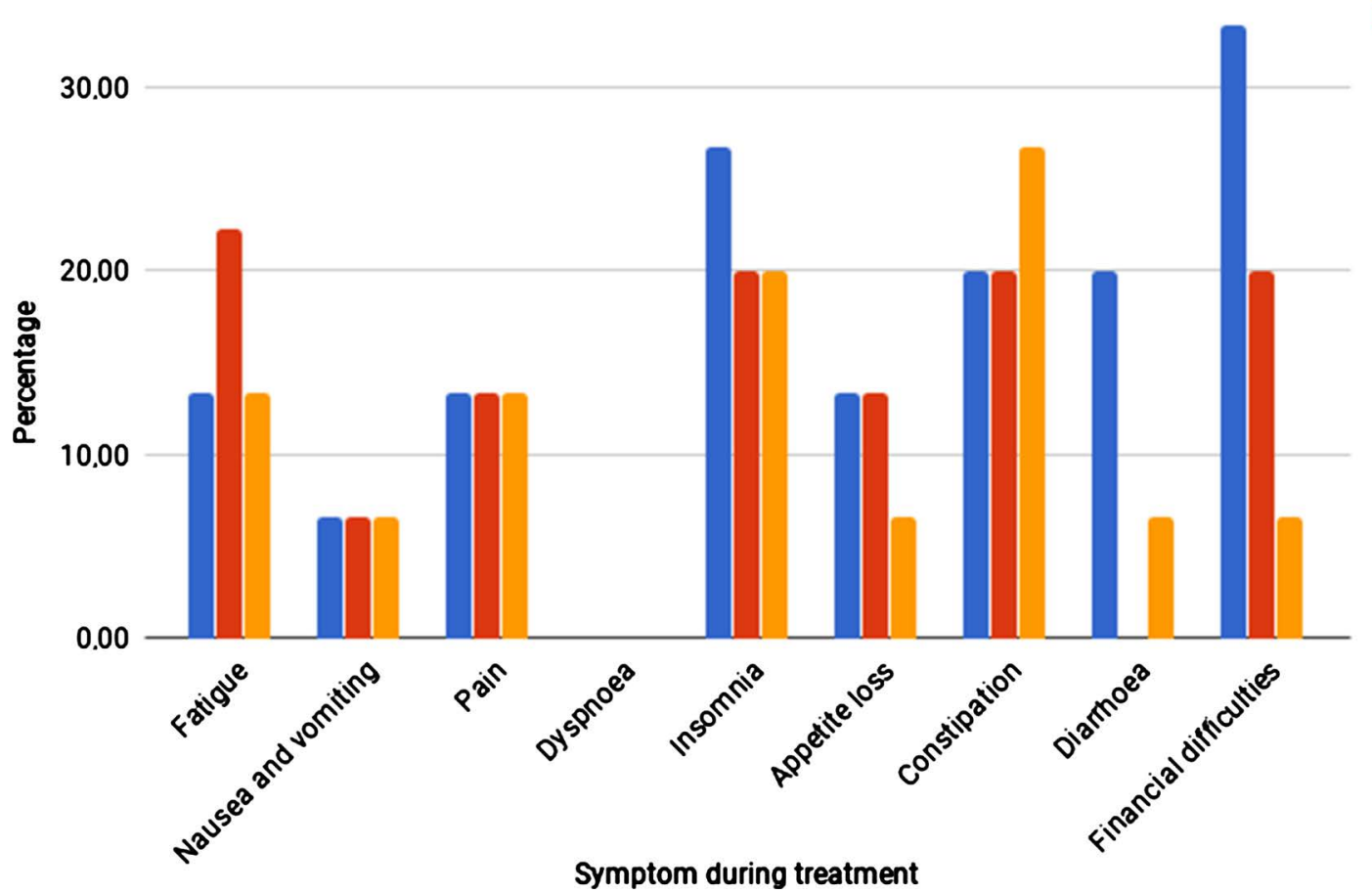

Figure 4. Symptoms scales/quality of life assessed at baseline, the 1st and 3rd month post initiation of therapy.

\section{Discussion}

This study reports the first documented experience in Latin America with the use of teleoncology to facilitate access to a highly complex cancer treatment (chemotherapy) in a remote and rural area, with improved quality of life and reduced financial and time burden for the patient.

Plan Esperanza, (the National Cancer Control Plan for Peru), has promulgated implementation strategies bringing oncology services to the most remote areas of the country according to standards similar to the comprehensive cancer care provided by INEN, through a collaborative alliance between institutions at the central and regional levels [10]. Peru is promoting the National Telehealth Network of the Ministry of Health (MINSA) in 118 hospitals nationwide to support remote medical care [16]. The technical standards for telehealth in Peru were published in 2009, with the first initiative being the provision of highly specialized remote care through teleoncology with the TELECHEMO module in Lamas [17].

The implementation of telemedicine in oncology has been carried out with great success in Australia, since 2012, with chemotherapy being administered in 6 rural medical centers aligned with the Cancer Center of Townsville in Queensland [18] [19]. The extended face-to-face visit complemented by teleoncology for consultations and supervision of chemotherapy administration [20] was ap- 
plied in Lamas, similar to the practice in Australian centers.

Sabesan (2012) reported the use of telechemotherapy in 158 patients with solid tumors, mainly breast cancer [18]. $69 \%$ of the patients with a median age 64 years) were treated with palliative intent; most had advanced cancer, all had solid tumors, with breast cancer being the most frequent, and 89\% (median age 48 years) received chemotherapy with palliative intent.

Chan (2015) noted no difference in tolerance comparing 89 patients receiving chemotherapy in the rural area of Mount Isa with 117 patients treated at the central hospital in Townsville [19]. The same group had shown previously that the administration of intense chemotherapy (doxorubicin-cyclophosphamide (AC), capecitabine-oxaliplatin (CAPOX)) in rural areas was safe and well-tolerated, with only 2 patients requiring central hospitalization [21]. Other regimens administered via telechemotherapy, including carboplatin-paclitaxel, gemcitabine, carboplatin- etoposide, bleomycin-cisplatin-etoposide (BEP) have also been reported [18] [19]. Our study, using the most common chemotherapy regimens for solid tumors, also demonstrated adequate safety and tolerance, with only one patient with severe thrombocytopenia requiring transfusion.

Teleoncology practice in Canada (2005-2007) reported cost savings of USD 245 in travel costs [22], comparable to the saving in our pilot project in 2015-18 (PEN 870 soles: USD 265). Thaker et al. reporting Australian experience, noted that after 605 teleoncology consultations for 147 patients over 56 months (March 2007 to November 2011), the total expense was USD 442,276; the total saved on travel, including accommodation and food, was USD 762,394 yielding a saving of USD 320,118 [23]. This evaluation took into account that each patient was accompanied, with services provided through six teleoncology centers with distances between 200 and $1400 \mathrm{~km}$, with $82 \%$ of patients treated at the center of teleoncology at $900 \mathrm{~km}, 10 \%$ at $200 \mathrm{~km}$ and only $4 \%$ belonging to the 1200 and $1400 \mathrm{~km}$ centers [23]. From Thaker's study, it can be inferred that the average saving per patient per consultation is USD 264, similar to our study, acknowledging that most of the patients were treated at a lesser distance in the Australian report. Whilst there may be greater savings in transportation in the Lamas study, a more precise conclusion would require comparative cost of living assessment between the two countries.

Travelling from San Martín to Lima represented an average cost of PEN 950, which, if avoided, would save PEN 870 (USD 265), a significant decrease in out-of-pocket expenses for the patient and family, being equivalent to the minimum wage of PEN 850 in Peru in 2016 [24]. It is consistent with the goal of Plan Esperanza to decrease the economic barriers for comprehensive cancer care throughout Peru, mainly for low-income patients [10]. Further, these savings are for each application of chemotherapy, which can be every 3 weeks for 4 or 6 cycles and in some cases weekly. Receiving treatment where they live maximizes personal, family, social, financial and labour continuity and sustainability.

Quality of life is commonly evaluated in clinical trials, but less frequently in 
retrospective studies. The EORTC QLQ-C30 version 3 has been validated in patients with prostate cancer with radiotherapy and/or hormonotherapy but not with chemotherapy [15]. For patients with early and locally advanced stages of breast cancer undergoing surgery, and radiotherapy or chemotherapy, better quality of life was reported in patients with early cancer [14]. Our study prospectively evaluated the quality of life for all patients enrolled, but not by cancer type or clinical stage, and noted a better global quality of life over the course of treatment. This is probably due to the effectiveness of treatment, received promptly in the local community without delays due to access and the high number of patients receiving therapy at INEN. Another significant finding in the evaluation of quality of life was the improvement in emotional and social well-being, possibly due to the avoidance of relocation to Lima, and the continuity of their care within their family and social environment.

\section{Limitations}

The present study has limitations due to a low number of patients included, the lack of sub classification of each type of cancer, the staging in early or advanced diseases and grouping according to age in young and older patients, and technical issues e.g. internet connection problems requiring cell phones to be used to communicate. It was impossible to determine the cost savings for companions when they did not interrupt their daily work activity due to the patient receiving treatment in Lamas.

In conclusion, using information and communication technology, a telechemotherapy module was successfully implemented in the Peruvian jungle, without adversely affecting the quality of life of patients. Neither patients nor family members needed to travel to Lima to receive their treatments, thereby avoiding travel, hospitality and food costs. This first program can be replicated in other rural and remote regions through non-specialized personnel and facilities, providing chemotherapy services equivalent to a tertiary center through trained health care professionals, supported, supervised and monitored through telemedicine.

\section{Conflicts of Interest}

The authors declare no conflicts of interest regarding the publication of this paper.

\section{References}

[1] World Health Organization (2015) Fact Sheet: Cancer. Fact Sheet 2015. http://who.int/mediacentre/factsheets/fs297/en/

[2] GLOBOCAN (2012) Estimated Cancer Incidence, Mortality and Prevalence Worldwide in 2012. International Agency for Research on Cancer, Lyon, France. http://globocan.iarc.fr/Default.aspx

[3] Lipsedge, M., Summerfield, A.B., Ball, C. and Watson, J.P. (1990) Digitised Video and the Care of Outpatients with Cancer. European Journal of Cancer and Clinical 
Oncology, 26, 1025-1026. https://doi.org/10.1016/0277-5379(90)90042-R

[4] Allen, A. and Hayes, J. (1995) Patient Satisfaction with Teleoncology: A Pilot Study. Telemedicine Journal, 1, 41-46. https://doi.org/10.1089/tmj.1.1995.1.41

[5] Hunter, D.C., Brustrom, J.E., Goldsmith, B.J., Davis, L.J., Carlos, M., Ashley, E., et al. (1999) Teleoncology in the Department of Defense: A Tale of Two Systems. Telemedicine Journal, 5, 273-282. https://doi.org/10.1089/107830299312023

[6] Vorozhtcov, G., Chissov, V., Danilov, A., Kazinov, V., Sokolov, V. and Frank, G. (1999) Perfect DiViSy Technology for Video Network in Medicine (Moscow Information Network for Teleoncology). Studies in Health Technology and Informatics, 64, 119-125.

[7] Marshall, C.L., Petersen, N.J., Naik, A.D., Vander Velde, N., Artinyan, A., Albo, D., et al. (2014) Implementation of a Regional Virtual Tumor Board: A Prospective Study Evaluating Feasibility and Provider Acceptance. Telemedicine and e-Health, 20, 705-711. https://doi.org/10.1089/tmj.2013.0320

[8] McCarthy, A., Hegney, D., Brown, L., Gilbar, P., Brodribb, T.R. and Swales, J. (2003) Characteristics of Chemotherapy Practice in Rural and Remote Area Health Facilities in Queensland. Australian Journal of Rural Health, 11, 138-144.

[9] Stevenson, L., Campbell, N.C. and Kiehlmann, P.A. (2003) Providing Cancer Services to Remote and Rural Areas: Consensus Study. British Journal of Cancer, 89, 821-827. https://doi.org/10.1038/sj.bjc.6601166

[10] Vidaurre, T., Santos, C., Gomez, H., Sarria, G., Amorin, E., Lopez, M., et al. (2017) The Implementation of the Plan Esperanza and Response to the imPACT Review. The Lancet Oncology, 18, E595-E606. https://doi.org/10.1016/S1470-2045(17)30598-3

[11] Hazin, R. and Qaddoumi, I. (2010) Teleoncology: Current and Future Applications for Improving Cancer Care Globally. The Lancet Oncology, 11, 204-210. https://doi.org/10.1016/S1470-2045(09)70288-8

[12] MINSA (MINSA) Declaran de interes nacional la Atencion Integral del Cancer y Mejoramiento del Acceso a los Servicios Oncologicos en el Perú y dictan otras medidas. DS N009-2012-SA, DIario el Peruano, Lima, Peru, 17.

[13] National Cancer Institute (2009) Common Terminology Criteria for Adverse Events. NCI, NIH, DHHS.

https://wiki.nci.nih.gov/display/VKC/Common+Terminology+Criteria+for+Advers e+Events

[14] Cerezo, O., Onate-Ocana, L.F., Arrieta-Joffe, P., Gonzalez-Lara, F., Garcia-Pasquel, M.J., Bargallo-Rocha, E., et al. (2012) Validation of the Mexican-Spanish Version of the EORTC QLQ-C30 and BR23 Questionnaires to Assess Health-Related Quality of Life in Mexican Women with Breast Cancer. European Journal of Cancer Care, 21, 684-691. https://doi.org/10.1111/j.1365-2354.2012.01336.x

[15] Arraras Urdaniz, J.I., Villafranca Iturre, E., Arias de la Vega, F., Dominguez Dominguez, M.A., Lainez Milagro, N., Manterola Burgaleta, A., et al. (2008) The Eortc Quality of Life Questionnaire QLQ-C30 (Version 3.0). Validation Study for Spanish Prostate Cancer Patients. Archivos Españoles de Urología, 61, 949-954. https://doi.org/10.4321/S0004-06142008000800017

[16] MINSA (2018) Minsa reúne a expertos para mejorar la atención médica a distancia a través de Telesalud. Ministerio de Salud del Perú. Lima, 2018.

http://www.minsa.gob.pe/index.asp?op $=51 \&$ nota $=26998$

[17] Ministerio de Salud (2009) Norma técnica de salud en telesalud. NTS N 067-MINSA/DGSP-V.01. Dirección General de Salud de las Personas. Dirección de 
Servicios de Salud. Lima, 20 p.

[18] Sabesan, S., Larkins, S., Evans, R., Varma, S., Andrews, A., Beuttner, P., et al. (2012) Telemedicine for Rural Cancer Care in North Queensland: Bringing Cancer Care Home. Australian Journal of Rural Health, 20, 259-264. https://doi.org/10.1111/j.1440-1584.2012.01299.x

[19] Chan, B.A., Larkins, S.L., Evans, R., Watt, K. and Sabesan, S. (2015) Do Teleoncology Models of Care Enable Safe Delivery of Chemotherapy in Rural Towns? The Medical Journal of Australia, 203, 406. https://doi.org/10.5694/mja15.00190

[20] Sabesan, S. (2014) Medical Models of Teleoncology: Current Status and Future Directions. Asia-Pacific Journal of Clinical Oncology, 10, 200-204. https://doi.org/10.1111/ajco.12225

[21] Pathmanathan, S., Burgher, B. and Sabesan, S. (2013) Is Intensive Chemotherapy Safe for Rural Cancer Patients? Internal Medicine Journal, 43, 643-649. https://doi.org/10.1111/imj.12083

[22] Palkhivala, A. (2011) Canada Develops Models of Teleoncology. Journal of the National Cancer Institute, 103, 1566-1568. https://doi.org/10.1093/jnci/djr449

[23] Thaker, D.A., Monypenny, R., Olver, I. and Sabesan, S. (2013) Cost Savings from a Telemedicine Model of Care in Northern Queensland, Australia. The Medical Journal of Australia, 199, 414-417. https://doi.org/10.5694/mja12.11781

[24] MINTRA (2016) Decreto Supremo que incrementa la Remuneración Mínima Vital de los trabajadores sujetos al régimen laboral de la actividad privada. Diario el Peruano, Lima, Perú, 1. 